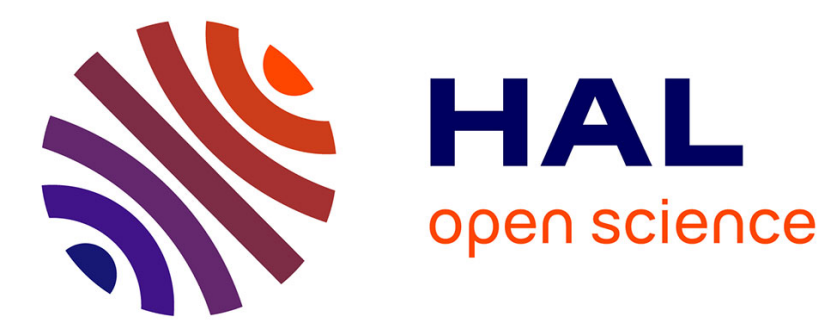

\title{
Photogrammetry Based Study of Ceramics Fragments
} Jean-Baptiste Barreau, Théophane Nicolas, Guillaume Bruniaux, Emilien Petit, Quentin Petit, Yann Bernard, Ronan Gaugne, Valérie Gouranton

\section{To cite this version:}

Jean-Baptiste Barreau, Théophane Nicolas, Guillaume Bruniaux, Emilien Petit, Quentin Petit, et al.. Photogrammetry Based Study of Ceramics Fragments. International Journal of Heritage in the Digital Era, 2014, 3, pp.643 - 656. 10.1260/2047-4970.3.4.643 . hal-01394971

\section{HAL Id: hal-01394971 https://hal.science/hal-01394971}

Submitted on 10 Nov 2016

HAL is a multi-disciplinary open access archive for the deposit and dissemination of scientific research documents, whether they are published or not. The documents may come from teaching and research institutions in France or abroad, or from public or private research centers.
L'archive ouverte pluridisciplinaire HAL, est destinée au dépôt et à la diffusion de documents scientifiques de niveau recherche, publiés ou non, émanant des établissements d'enseignement et de recherche français ou étrangers, des laboratoires publics ou privés. 


\title{
Photogrammetry Based Study of Ceramics Fragments
}

\author{
J-B. Barreau ${ }^{1,4,5,6}$, T. Nicolas ${ }^{2}$, G. Bruniaux ${ }^{3,5}$, E. Petit ${ }^{3,5}$, Q. Petit ${ }^{1,6}$, \\ Y. Bernard ${ }^{3,5}$, R. Gaugne ${ }^{3,6}$ and V. Gouranton ${ }^{4,6}$ \\ ${ }^{1}$ CNRS, ${ }^{2}$ Inrap, ${ }^{3}$ Université de Rennes 1, ${ }^{4}$ INSA Rennes, \\ ${ }^{5} \mathrm{CReAAH},{ }^{6}$ IRISA/Inria
}

\begin{abstract}
Reconstitution of whole ceramics from fragments is a true priesthood for ceramographers. This activity remains mainly handled by manual sketching and can be very time consuming. However, more and more tools and workflows provide digital solutions, based on 3D technologies, to assist such tasks. In this paper, we present an application of photogrammetry on ceramic fragments from two excavation sites located in Brittany, France. This study was required by two ceramics specialists and conducted in CReAAH, a French research center in archaeology, archaeosciences and history. The 3D restitution by photogrammetry of these different fragments allowed reconstructions of the original shapes of the potteries or at least to get to as close as possible. We furthermore used the resulting 3D models of the ceramics to compute various metrics required by the ceramographers. In collaboration with IRISA, a French research center in computer science, we designed and generated a presentation support using a 3D printer. This work is based on affordable tools and illustrates how 3D technologies can be quite easily integrated in archaeology process with limited financial resources, to obtain useful results for the study and analysis of such artefacts.
\end{abstract}

\section{INTRODUCTION}

Today, photogrammetry and 3D modelling are an integral part of the methods used in archeology and heritage management. They provide answers to scientific needs in the fields of conservation, preservation, restoration and mediation of architectural, archaeological and cultural heritage [2] [6] [7] [9]. Photogrammetry on ceramic fragments was one of the first applications contemporary of the development of this technique applied in the archaeological community [3]. More recently and due to its democratization, it was applied more generally to artifacts [5]. Finally joined today by the rise of 3D printing [8] [10], it can restore fragmented artifacts [1] [12]. These examples target one or several particular objects and use different types of equipment that can be expensive. These aspects can put off uninitiated archaeologists. So it would be appropriate to see if these techniques could be generalized to a whole class of geometrically simple and common artifacts, such as ceramics.

From these observations, associated to ceramics specialists with fragments of broken ceramics, we aimed at arranging different tools and methods, including photogrammetry, to explore opportunities for a cheap and attainable reconstruction methodology and its possible applications. Our first objective was to establish a protocol for scanning fragments with photogrammetry, and for reconstruction of original ceramics. We used the digital reconstitutions of the ceramics we got following our process to calculate some metrics and to design and $3 \mathrm{D}$ print a display for the remaining fragments of one pottery. 


\subsection{Archaeological context}

The archaeological material studied in this work consists in domestic ceramics from an Iron Age site in Rezé (Loire-Atlantique - France) and from a Bronze Age site in Lannion Penn An Alé (fig 1).

\section{Rezé ceramics}

The study addresses seven vases resulting from a set of archaeological materials excavated in the "Jaguère" site at Reze (Loire-Atlantique, France). Dating from the second Iron Age, these ceramic artifacts were initially studied by Charlotte Choisy-Guillou (Université de Bretagne Sud). The seven vases are entitled Gr1C, Gr5E, MGr2E, MGr11D, Gr1E, Gr7D, and Gr8B. For all vases, we disposed of one single fragment, except for the Gr8B for which we had three fragments.

\section{Lannion Penn An Alé ceramic}

The study addresses one container from a set of archaeological materials revealed during a preventive excavation operation on the "Penn an Alé" activities zone in Lannion (Côte d'Armor, France) performed by Inrap (the French National Institute for Preventive Archaeological Research). This operation led on nearly 3.5 hectares, under the guidance of S. Blanchet, allowed to uncover an archaeological site from the Bronze Age; attesting a long human occupation between 1800 and $1200 \mathrm{BCE}$. It gave an abundant ceramic set which is a real baseline for the region (fig 1).
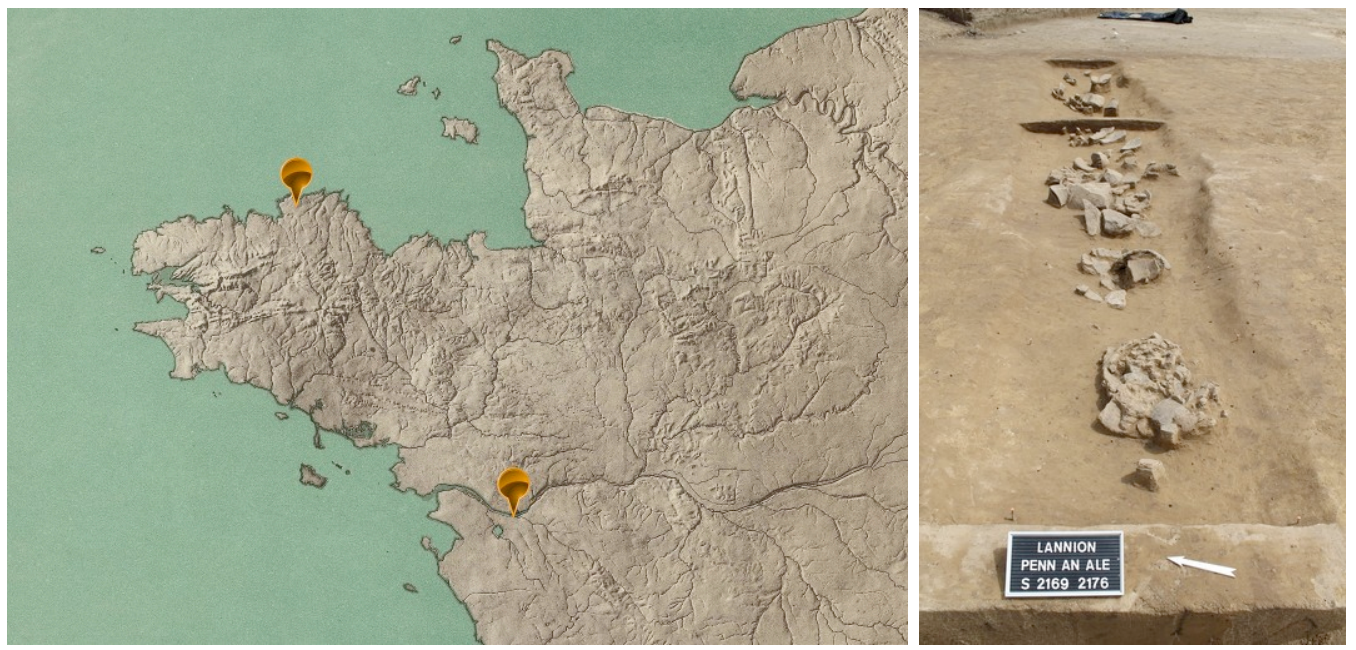

Figure 1. Location of sites and "Penn an Alé" site (@ Inrap)

\section{PROCESS OVERVIEW}

The global workflow designed for the study of ceramics presented in this paper consists in five main steps, presented in Figure 2.:

1. First, in the step "Camera capture", ceramic fragments are scanned with photos. This activity is detailed in sections 3.1 and 3.2.

2. In the step "Picture processing", the pictures are processed with a photogrammetry software to generate a point cloud. This step is detailed in section 3.3.

3. In the step "Mesh generation", a highly detailed mesh is generated for each fragment, scaled and textured, as detailed in section 3.4 . 
4. In the step "Shape reconstruction", full shapes of the ceramics are extrapolated from the meshes of the fragments. The extrapolated shapes are the used to get a full volume on which measurements can be taken. This step is detailed in section 4.

5. The last step "Mesh processing and 3D printing" aimed at building a fragment support for the ceramics of "Penn an Alé", using a 3D printer, as presented in section 4.3.

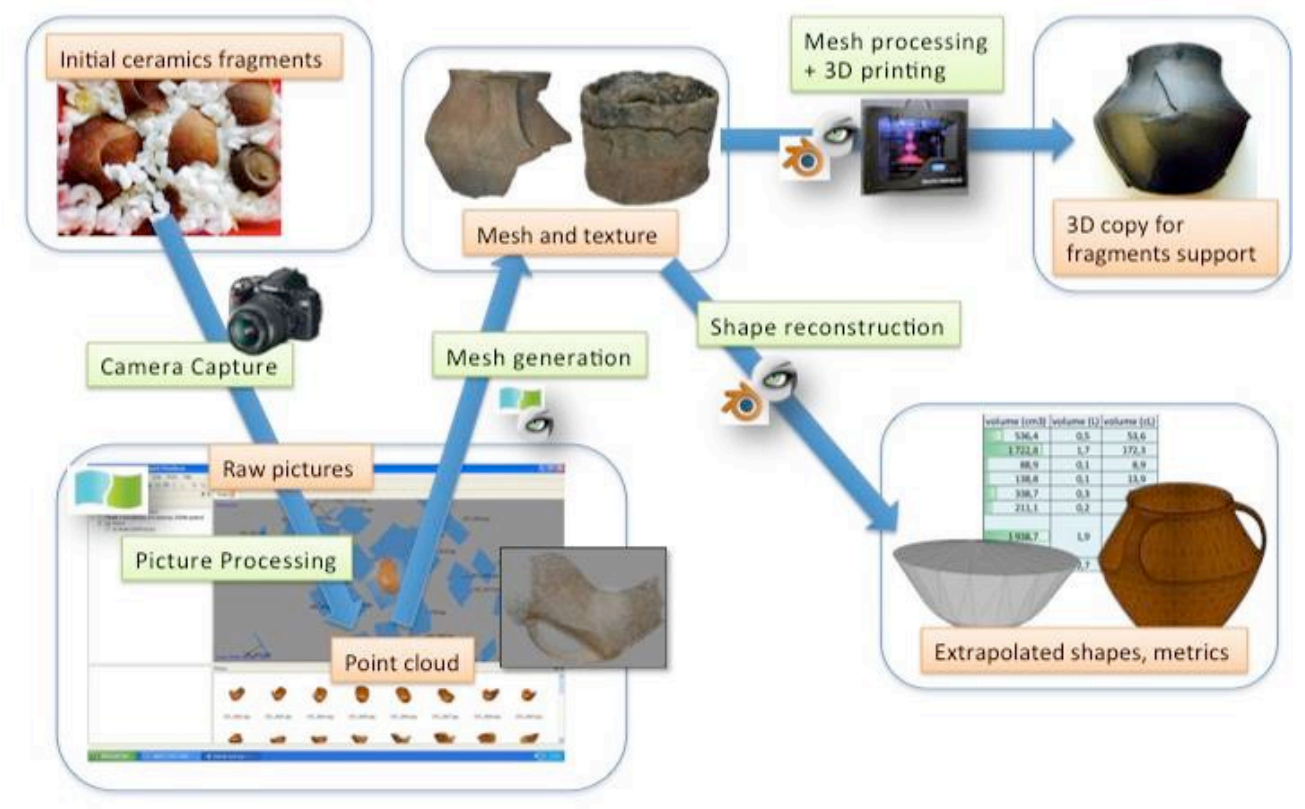

Figure 2. Process diagram

\section{3D DIGITIZATION}

We present now the protocol we followed to perform the 3D digitization of ceramic fragments by photogrammetry, the different steps to obtain satisfactory results in 3D reconstruction, the technique used to evaluate the volume of ceramics, and the problems we encountered during the work.

\subsection{Equipment}

As the study is based on a reconstitution of archaeological ceramics with photogrammetry, it was essential to use a high quality digital single-lens reflex camera with a good lens and good image resolution. Indeed, this allows to obtain very good quality photos and better results during the search for common points with the photogrammetry software. We used a Nikon D60 Digital SLR to take photos of the various ceramic fragments [11]. Its technical features include a 10megapixel CCD sensor, an $18-55 \mathrm{~mm}$ optical AF-S with a $40 \mathrm{~mm}$ focal distance and a Nikon autofocus module Multi-Cam 530 (3 AF points).

The environment used to take photos was composed of two light tables, a white background with its support and a halogen lamp (fig 3). This equipment allowed getting a light from below and above to minimize the shadow games. Homogeneity of brightness was difficult to obtain with only one single halogen lamp. This was a major problem because we needed a uniform and constant light regardless of the orientation of the shooting. Indeed, if the light intensity varies too much, then common points determined on a photo by photogrammetry software will not be the same from one photo to another. 

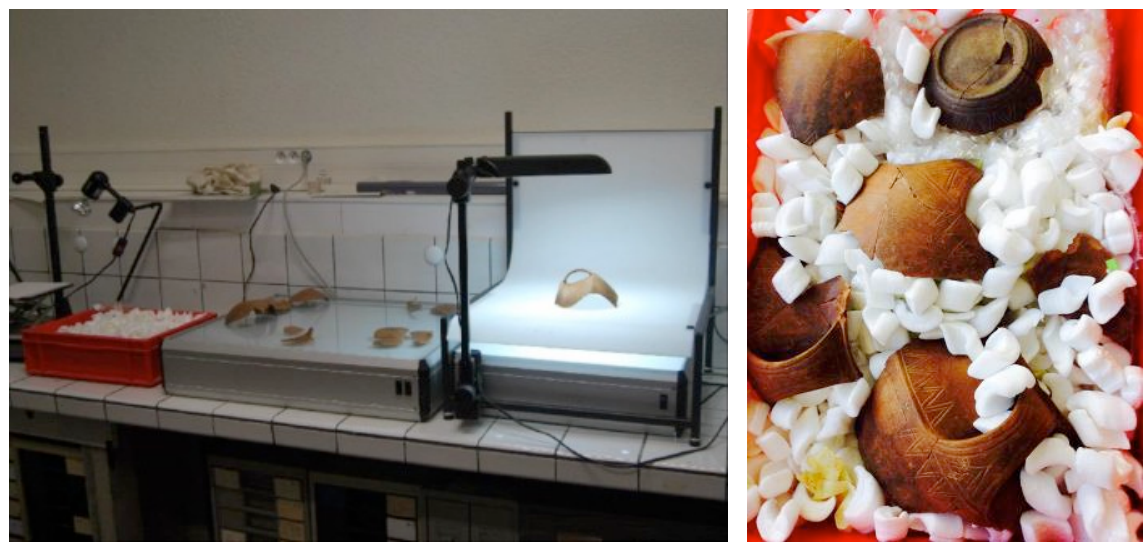

Figure 3. Shooting equipment and ceramic fragments

\subsection{Camera capture}

The goal is here to shoot the object rotating on itself in order to get every viewing angle [4]. We took a first series of photos, describing a semicircle, with a distance camera-object as regular as possible. Then, we rotated the object through $180^{\circ}$ in order to complete the series and to get a first coverage of the object. Other series of photographs were taken from different angles to cover a maximum area. Following this procedure, five series of captures were performed: one on the top, one at $45^{\circ}$ over the top, one horizontal, one at $45^{\circ}$ over the bottom, and the last, at bottom (Fig. 4).

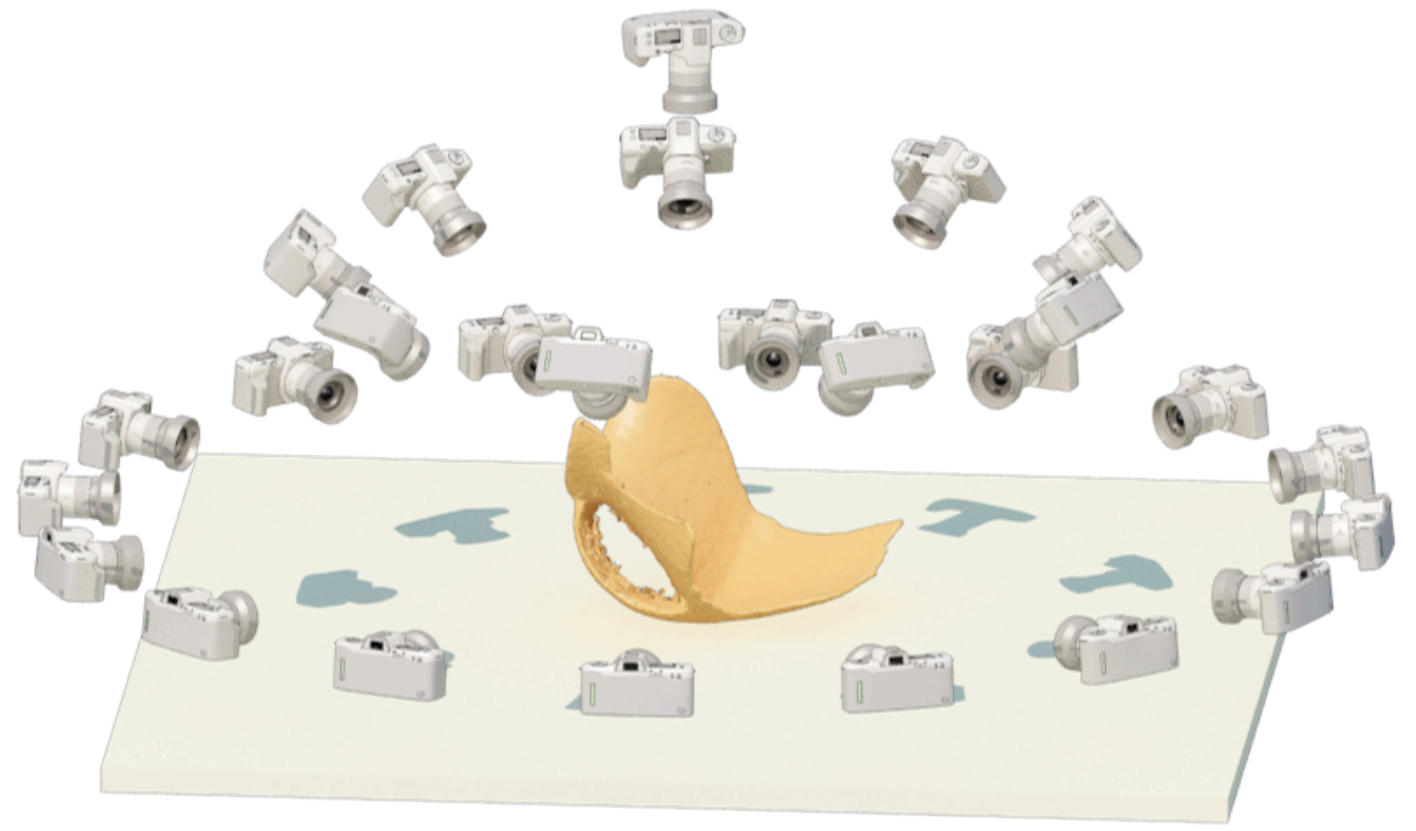

Figure 4. Different camera positions for the series top, top $45^{\circ}$, and horizontal. 


\subsection{Picture processing}

For $3 \mathrm{D}$ restitution, we used the photogrammetry software Agisoft PhotoScan version 0.8 .3 beta 64bits. This software has been chosen for its ease of use and its ability to generate highly detailed 3D models. Photos of the object were then imported into PhotoScan, in order to rebuild $3 \mathrm{D}$ information, in the form of point clouds. Before starting the search for common points, a mask constraint (clipping of the object) must be included on each photo to focus the calculation only on the object and not all the environment. The search for common points and pictures alignment is then performed with a "strong" accuracy. Figure 5 illustrates picture alignment in Photoscan interface.

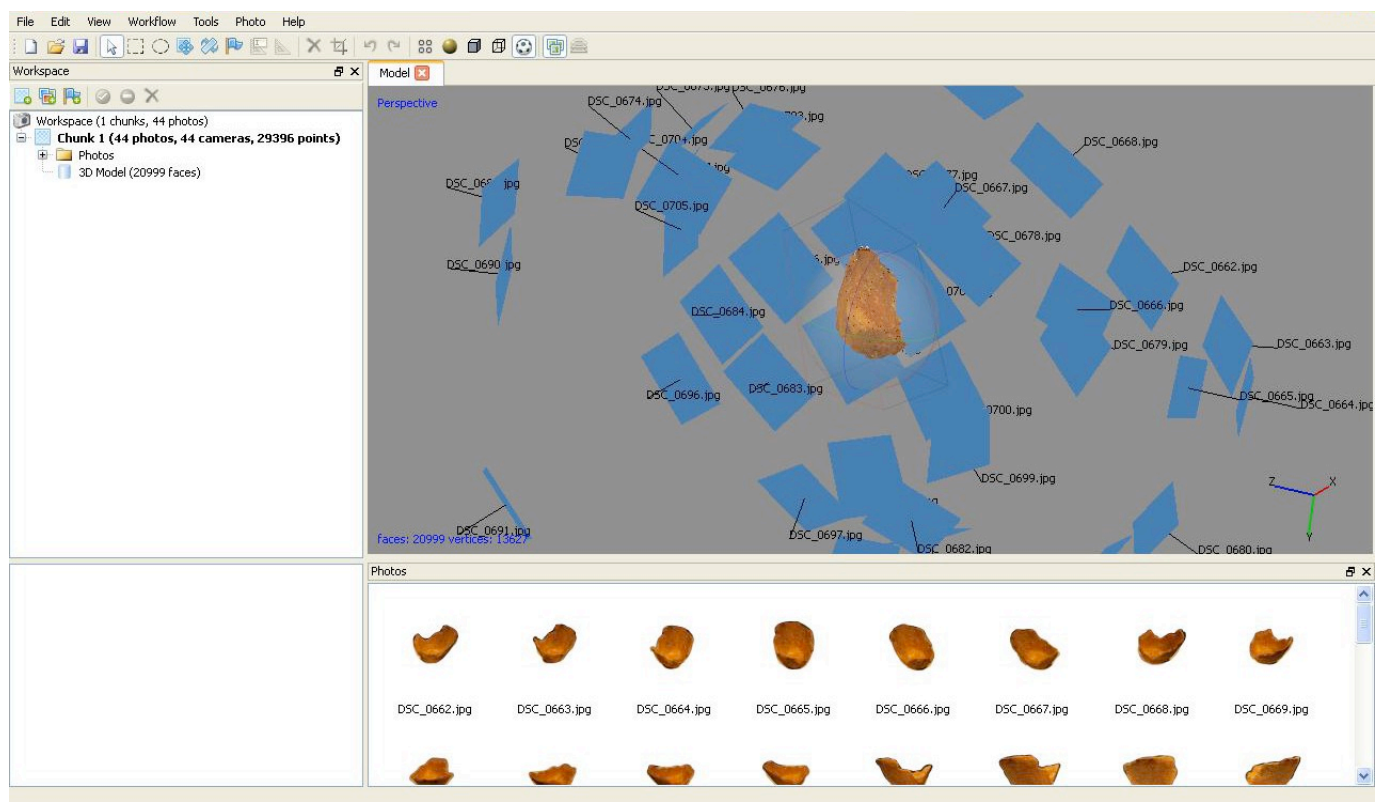

Figure 5. Picture alignment in PhotoScan interface

Correct scaling of the object is usually performed directly in the software by placing two markers whose distance is known, on a photo of the object. The distance between the markers is set in Photoscan as a reference distance that enables the software to generate a $3 \mathrm{D}$ model with a correct scale. This functionality requires a sufficiently uniform light, which was not the case in our installation. According to this limitation, we chose to handle the scaling of the model in another further step. The maximum number of common points was set to 60000 instead of 40000 (default) to get a better rendering. The generated point cloud, resulting from the determination of connection points and photos alignment, allowed to verify the coherency of the digital output with respect to the object (fig 6).
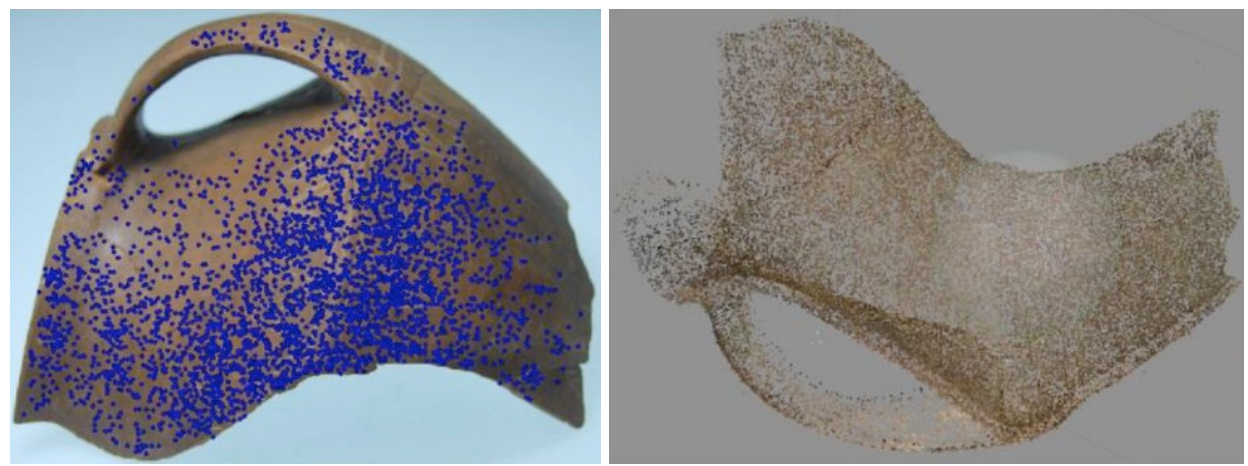

Figure 6. Piece of the Bronze Age ceramic with connection points (blue) determined by PhotoScan / Resulting point cloud 


\subsection{Mesh generation}

The goal of this step is to generate a textured mesh for each fragment. The generation of geometries and textures was processed in PhotoScan with "arbitrary" option for the object type, "high" for the quality and "sharp" for geometric precision. The number of expected surfaces was set to 250000 . The color of the mesh was computed from the color information contained in the points cloud. Photoscan generated the texture from several pieces of images extracted from the pictures, and applied it on the surface of the mesh (fig 7). The options for this step were a "generic" mapping mode and "average" fusion mode.
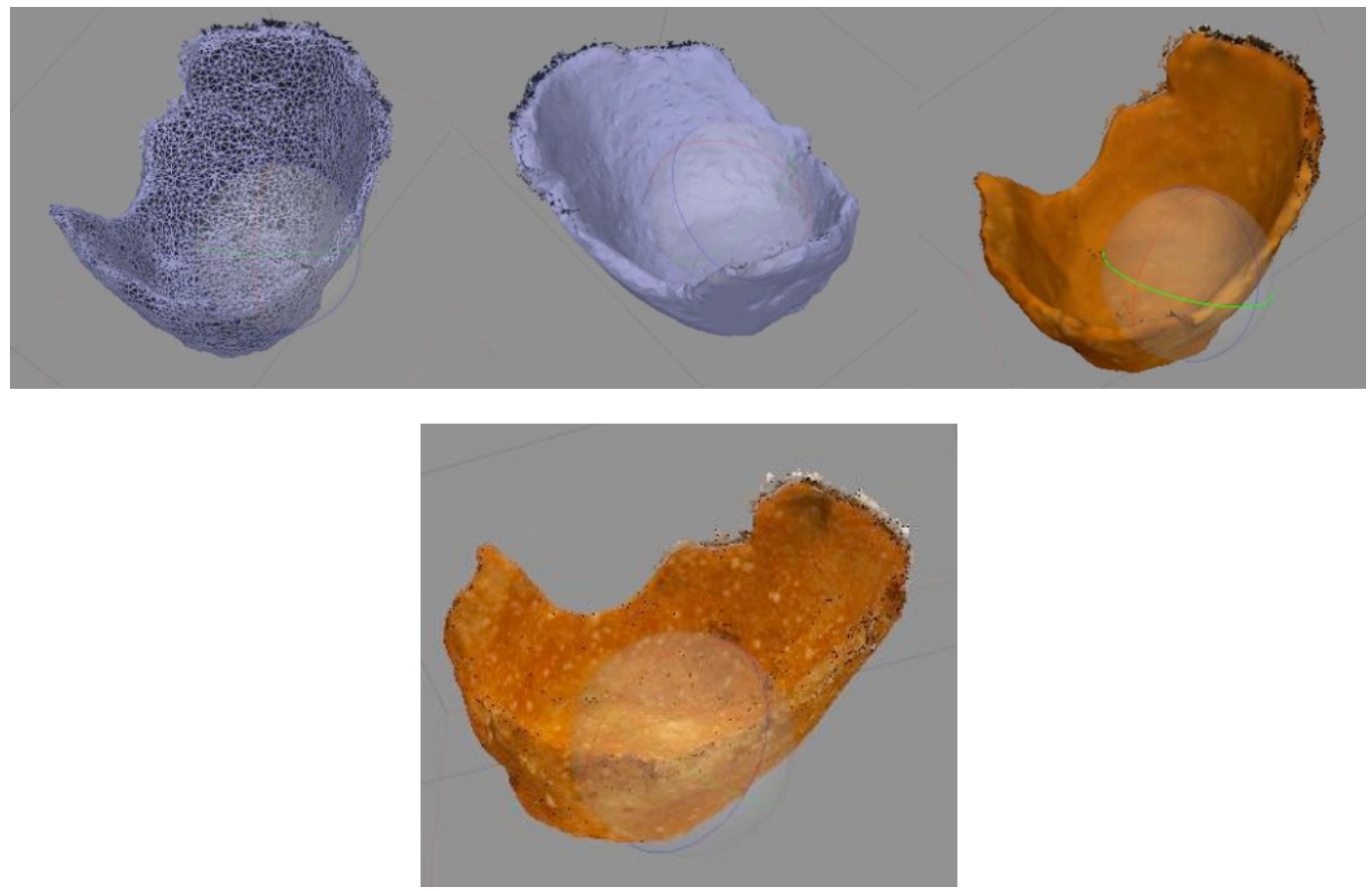

Figure 7. Raw mesh (top left) / smoothed mesh (top middle) / mesh with colors (top right) / textured meshs (bottom)

The resulting mesh was then exported in ".obj" format and imported in Meshlab to perform scaling. A measure of distance was computed with the tool "rule" between two points whose real distance is known. The ratio between the real distance and the measured distance on the mesh provided the proportionality factor between these two distances. Thanks to the "Transform: scale" MeshLab function, distances on the $\mathrm{X}, \mathrm{Y}$ and $\mathrm{Z}$ axis were multiplied by this factor achieving the correct scaling of the mesh.

\section{RECONSTRUCTIONSANDAPPLICATIONS}

\subsection{Technical environment}

3D reconstruction from scanned fragments was performed via Blender software. The scale and volume calculation were processed with MeshLab software.

\subsection{Rezé ceramics}

In the case of the Rezé ceramics, the available fragments cover only a partial part of each object. Therefore, the reconstruction was theoretical and performed by extrapolating the different shapes from the fragments in Blender. Most of the fragments contain a part of the lip, the neck, the edge, the body or the bottom. Therefore, if the fragment has a piece of ceramic bottom, it can be 
aligned with the horizontal plane XY for an easier handling. The lip of the ceramic fragment has a curvature. Using this curvature, a circle (circular mesh) was created and the perimeter of this circle adjusted to coincide perfectly with the contour of the lip. This provided the theoretical circumference of the upper ceramic part. The same operation was repeated several times by shifting the other circles on the Z-axis which were then adjusted on the other parts of the ceramic (kept and visible on the fragment). Therefore, the assembly of these circles on the fragment provided the "skeleton" of the ceramic. Once this frame done, it was imported in MeshLab again to calculate the volume of the ceramic. The "convex hull" function, in the "remeshing, simplification and reconstruction" tab allowed to create a mesh from the different circles of the frame (fig 8). This mesh, constituting a completely closed shape, was used to calculate a volume with the "compute geometric measures" function. The table 1 gathers the characteristics of the reconstitutions of the different Rezé ceramics.
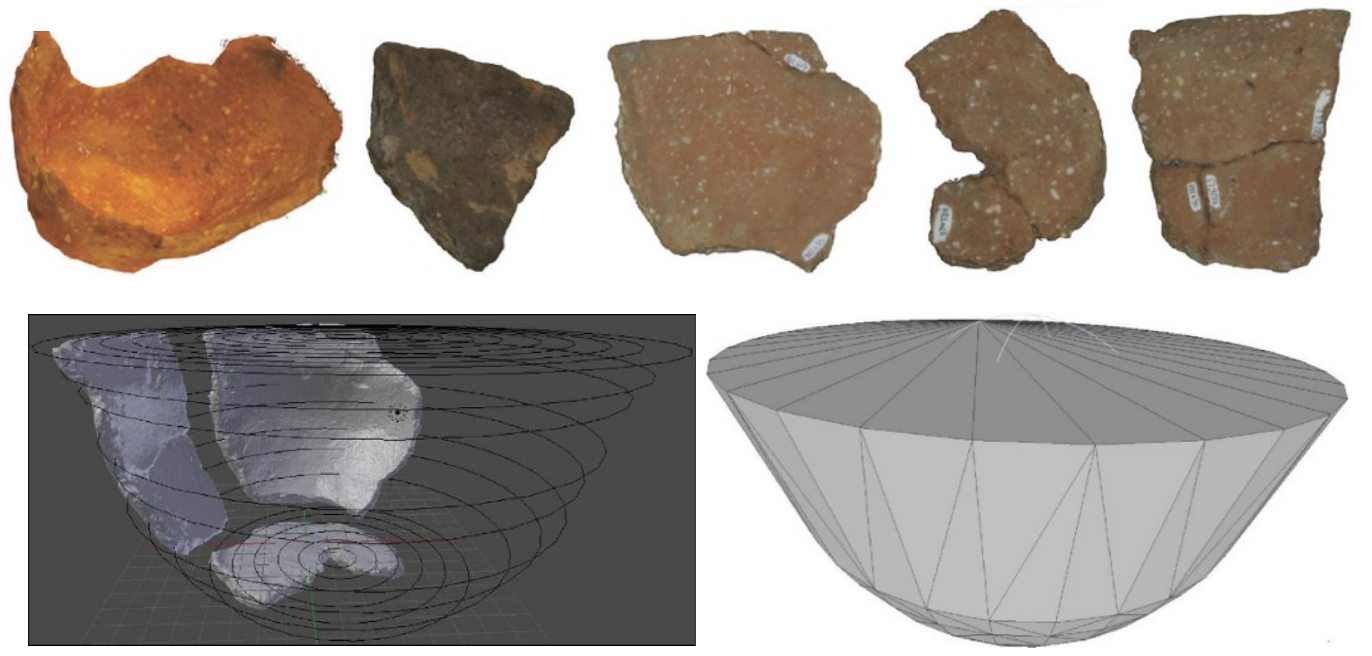

Figure 8. Fragments of eating ceramics reconstituted by photogrammetry / Frame of circles aligned along the $Z$ axis and dimensioned according to the curvature of the fragments / "convex hull" function on the Gr8B ceramic

\begin{tabular}{lllllll}
$\begin{array}{l}\text { Ceramic } \\
\text { name }\end{array}$ & $\begin{array}{l}\text { Number of } \\
\text { photos }\end{array}$ & $\begin{array}{l}\text { Number of } \\
\text { points (point } \\
\text { cloud) }\end{array}$ & $\begin{array}{l}\text { Number } \\
\text { of } \\
\text { surfaces }\end{array}$ & $\begin{array}{l}\text { Number } \\
\text { of } \\
\text { vertices }\end{array}$ & $\begin{array}{l}\text { Calculation } \\
\text { time }\end{array}$ & $\begin{array}{l}\text { Volume } \\
\text { (cm3) }\end{array}$ \\
\hline Gr1C & 36 & 24101 & 249999 & 130234 & $40 \mathrm{~m}$ & 536,4 \\
Gr5E & 78 & 55470 & 246768 & 128077 & $1 \mathrm{~h} 14 \mathrm{~m}$ & 1722,8 \\
MGr2E & 89 & 31204 & 249999 & 139674 & $52 \mathrm{~m}$ & 88,9 \\
MGr11D & 75 & 18354 & 250000 & 129272 & $43 \mathrm{~m}$ & 138,8 \\
Gr1E & 44 & 29396 & 17911 & 11036 & $39 \mathrm{~m}$ & 338,7 \\
Gr7D & 62 & 45250 & 154286 & 77517 & $41 \mathrm{~m}$ & 211,1 \\
Gr8B & 111 & 59623 & 250000 & 149449 & $1 \mathrm{~h} 15 \mathrm{~m}$ & 1938,7 \\
\hline
\end{tabular}

Table 1. Summary of the characteristics of each reconstituted ceramic fragments 


\subsection{Lannion Penn An Alé ceramic}

This Bronze Age ceramic is "almost" full, so we tried to assemble the different fragments in Blender. Fragments of ceramic having a part of the lip were first assembled and wedged on a circle perfectly matching its shape. The other pieces were then imported and positioned one by one. One difficulty, however, was met with several small fragments. For them, only the inner or outer part of the fragment was reconstituted. The reasons for this failure are many and difficult to determine. Indeed, this can be induced by low quality of light, insufficient image quality or a too thin thickness of the ceramic fragments that corrupted the detection of common points on the edges. To solve this problem, the inner and outer parts were rescanned separately and then scaled in MeshLab. The two parts were then positioned parallel to the horizontal plane XY, superimposed on each other by playing with a rotation on the $\mathrm{Z}$ axis, and then merged by sliding the inner part relative to the $\mathrm{Z}$ axis.

The reconstruction approach was different than in Rezé context. After deleting the handles, we used the function "Surface reconstruction: Poisson" in Meshlab allowing to extrapolate the initial ceramic shape from the assembly of fragments (fig 9). This shape was used to compute the volume of the ceramic whose result is $2742,9 \mathrm{~cm} 3$.
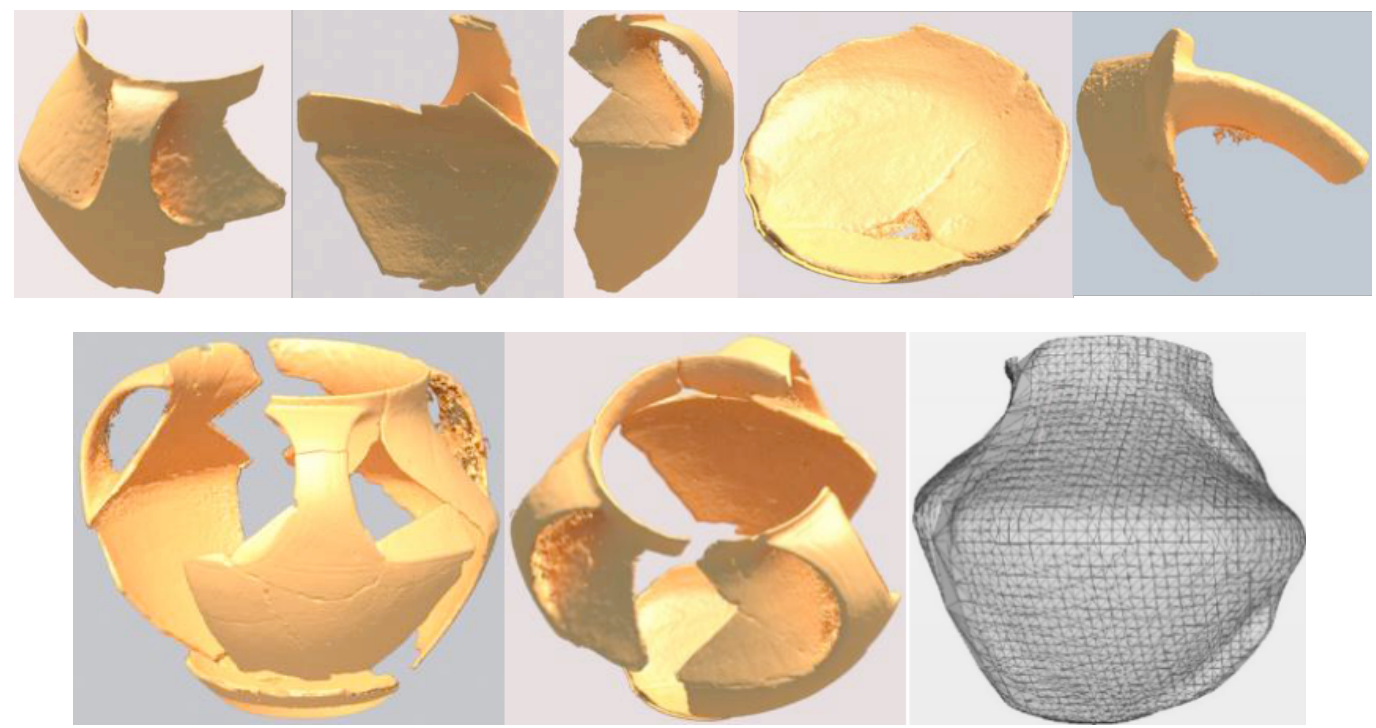

Figure 9. Separated parts / reconstruction step / reconstruction with the function "Surface reconstruction: Poisson"

A last step of the work consisted in using the generated shape to build a support for the fragments, in order to get a 3D tangible representation of the pottery. We used a $3 \mathrm{D}$ printer MarkerBot Replicator 2x, which is an ABS printer, to produce the support display. The mesh required some corrections made by a graphic designer under 3DSmax (fig 10), because the Poisson reconstruction introduced some approximation at the frontiers between the real fragments and the computed shape. 

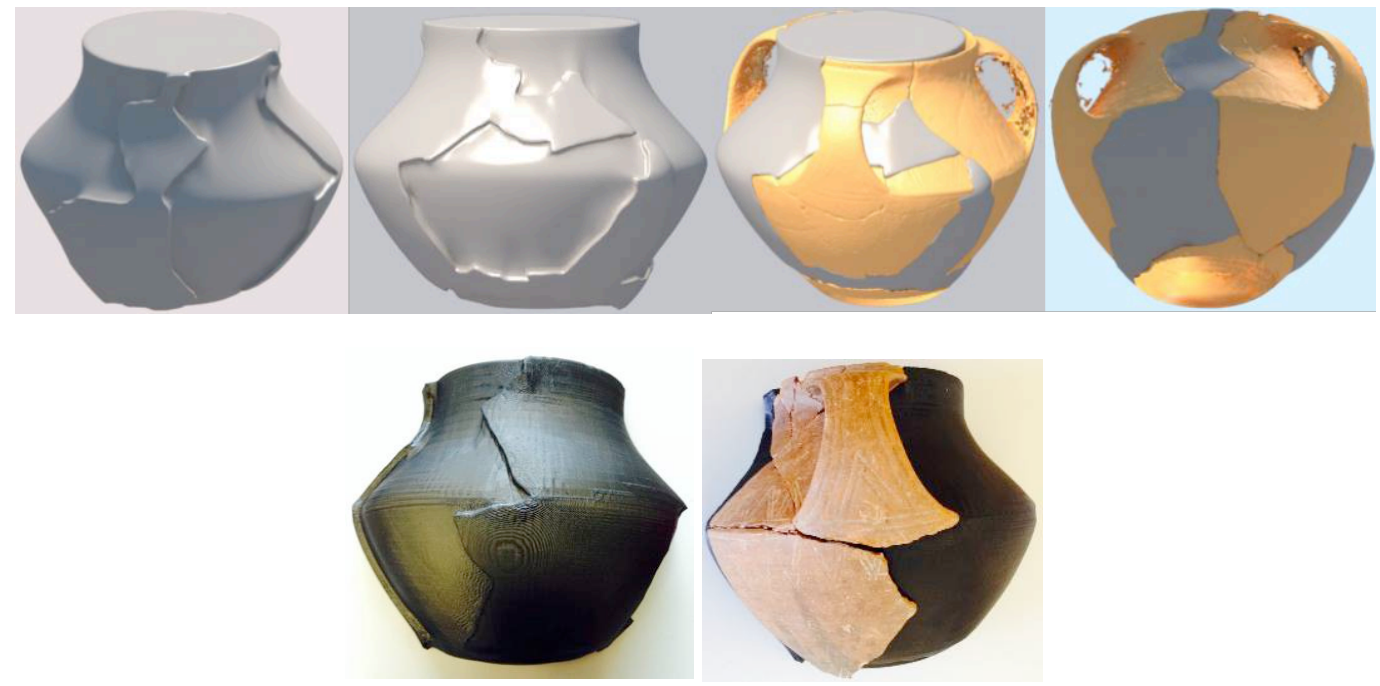

Figure 10. 3D models of the display without and with fragments / empty display / display with fragments

\section{DISCUSSION}

The digitization process has highlighted difficulties often masked by the apparent simplicity of photogrammetry. However, we believe we reached our goal regarding the very low cost of the digitization of fragments, and the resulting data and information.. The different approaches about reconstruction discussed here provided practical useful data for the analysis work performed by archaeologists. The volumes estimate, the $3 \mathrm{D}$ visualization of the shape, and the tangible 3D presentation represented concrete help in the study of the ceramics.

The $3 \mathrm{D}$ printer used for this work is a relatively inexpensive one, recently bought by the computer science laboratory involved in the project. The generation of a support display for the Lannion ceramic was a proof of concept for presenting fragments physically held around the content. However, problems have arisen. Because the Bronze Age ceramic is too large for this printer, especially because of the size of the handles, we had to print the support in two parts. In addition, the Poisson reconstruction of the internal volume of the ceramic generated approximations, which implied that the fragments did not exactly fit the display. Modifications on the $3 \mathrm{~d}$ model of the display were required to match the shape of the fragments.

The result of this experimental work convinced us that the production of such display could well be generalized within the museum community due to its low cost. A first reflection on its use has led us to believe that it would be wise to add on top of the display (not covered by a fragment) signs indicating metadata in the print-ready $3 \mathrm{D}$ model (fig 11).
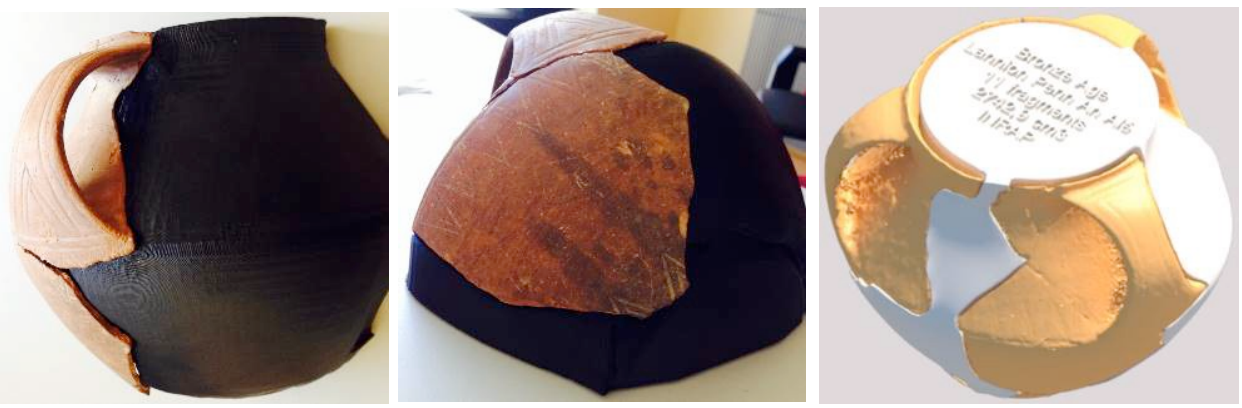

Figure 11. Separated part of the display / metadata inscription on the $3 \mathrm{~d}$ model 


\section{CONCLUSION AND FUTURE WORKS}

We proposed a simple protocol to digitize fragments of ceramics. This protocol is accurate enough to provide a digital reconstitution of ceramics with heterogeneous morphologies and compute basic metrics. Furthermore, from the digital reconstitution of the Lannion Penn An Alé ceramics, we designed and 3D printed a display for the remaining fragments. This kind of display could be used for exhibition of artefacts in museums.

The next step of this work is to validate these methods on more ceramics. To do this, we must solve the problems of accuracy in digitization and printing of large volumes. We also wish to extend these methods to other kinds of less symmetrical archaeological fragmented artifacts. Finally, it would be interesting to integrate museologists to our future works on $3 \mathrm{D}$ printed displays.

\section{REFERENCES}

[1] L. Arbace, E. Sonnino, M. Callieri, M. Dellepiane, M. Fabbri, A. I. Idelson, and R. Scopigno, Innovative uses of $3 \mathrm{D}$ digital technologies to assist the restoration of a fragmented terracotta statue, Journal of Cultural Heritage Volume 14, Issue 4, 2013, pp. 332-345

[2] J-B. Barreau, R. Gaugne, Y. Bernard, G. Le Cloirec and V. Gouranton, The West Digital Conservatory of Archaeological Heritage project, Digital Heritage International Congress 2013, Vol. 1, pp 547-554

[3] M. Kalantari and M. Kasser, Implementation of a Low-Cost Photogrammetric Methodology for 3D Modelling of Ceramic Fragments, XXI International CIPA Symposium, Athens, Greece, 2007, pp. FP079

[4] K. Kraus and P. Waldhäusl , Manuel de photogrammétrie - principes et procédés fondamentaux, Paris: HERMES, 1998, pp. 394

[5] C. Nicolae, E. Nocerino, F. Menna, and F. Remondino, Photogrammetry applied to problematic artefacts, The International Archives of the Photogrammetry, Remote Sensing and Spatial Information Sciences, Volume XL-5, 2014 ISPRS Technical Commission V Symposium, Riva del Garda, Italy, pp. 451-456

[6] A. Arles, F. Busdraghi, J. Guyot, and J. Heckes, La photogrammétrie appliquée à l'archéologie minière : premier essai, IRAMAT-CNRS, Université d'Orléans, Centre Ernest Babelon, 2011, pp. 25

[7] R. Héno, L. Borel, E. Alby, and A. Favre-Brun, Archéologie et photogrammétrie - Les nouveaux potentiels, Géomètre, $\mathrm{n}^{\circ} 2075,2010$, pp. 26-40

[8] F. P. Rutland and A. La Pensée, Non-contact 3D laser scanning as a tool to aid identification and interpretation of archaeological artefacts; the case of a Middle Bronze Age Hittite dice, National Museums, 2011, Liverpool

[9] S. Varea, Photogrammétrie et muséologie - Les sèvres du musée de Rouen, Revue XYZ, n 108, 2006, pp. 23-30

[10] A. Galt, The Rise of 3-D printing in Archaeology, University of Southampton - Archaeological Computing Research Group, 2014, http://acrg.soton.ac.uk/blog/3790

[11] R. Labracherie, Test du reflex Nikon D60, Focus Numérique, 2008, http://www.focus-numerique.com/test48/reflex-nikon-d60-presentation-caracteristiques-1.html

[12] A. Powell, An ancient statue, re-created, Harvard Gazette - December 4, 2012, http://news.harvard.edu/gazette/story/2012/12/an-ancient-statue-re-created 